\title{
Pancreatic Krukenberg Tumor of the Ovary: Case Report
}

Dahmane Hicham*, Alazaoui F, Mouatassim Z, Chakiri A, El Malki HO, Chefchaouni M, Ifrine L, Belkouchi A

Chirurgie A, Ibn Sina Hospital, Mohammed V University, Rabat, Morocco

DOI: $10.36347 /$ sjmcr.2020.v08i07.003

| Received: 06.07.2020 | Accepted: 13.07.2020 | Published: 16.07.2020

*Corresponding author: Dahmane Hicham

Abstract

Krukenberg's tumors are rare malignant tumors of the ovary, often bilateral and secondary to cancer of the stomach, mucosal secreting in $90 \%$ of cases. We are reporting a case in our unit of a krukenberg with a primary pancreatic tumor. The diagnosis and management of krukenberg tumor is complex and should involve an interprofessional team that includes hospice, palliative care nurse, pain specialist, oncologist, surgeon, pathologist, and radiologist. In all cases, this is metastatic disease and the patients are frail and debilitated. Aggressive surgery is not recommended as it does not extend life span.

Keywords: Krukenberg, pancreas, metastasis.

Copyright @ 2020: This is an open-access article distributed under the terms of the Creative Commons Attribution license which permits unrestricted use, distribution, and reproduction in any medium for non-commercial use (NonCommercial, or CC-BY-NC) provided the original author and source are credited.

\section{INTRODUCTION}

Krukenberg's tumors are rare malignant tumors of the ovary, often bilateral and secondary to cancer of the stomach, mucosal secreting in $90 \%$ of cases. We are reporting a case in our unit of a krukenberg with a primary pancreatic tumor to illustrate particuliarities of this entity et his ability to simulate primary mucinous ovarian carcinoma.

\section{Patient and Observation}

We repport a case of a 59 years old women, admitted for management of a cholestatic jaundice evolving from a month and a half associated with epigastric transfixing pain and an alteration of the general state with weight loss of $13 \mathrm{~kg}$ in 9 months.

The biological assessment was without particularities at the time of admission. Abdominal computed tomography showed a process of the head of the pancreas associated with an ovarian mass.
MRI showed a diffuse swelling of the pancreatic gland associated with dilation of the main bile duct to $13 \mathrm{~cm}$ and minor dilation of the intrahepatic bile ducts with the presence of a predominantly cystic pelvic mass measuring $16 \times 17 \times 9 \mathrm{~cm}$ and presence of signs of peritoneal dissemination (Figure-1).

Echoendoscopy showed an ishtmocephalic pancreatic lesion of $24 \mathrm{~mm}$, the biopsy returned in favor of a ductal adenocarcinoma.

RCP decision was to opérate the patient. Surgical exploration found peritoneal carcinosis and a solidocystic mass of the left ovary of $20 \mathrm{~cm}$ of long axis. We decide to perform an anexectomy (Figure-2) and a palliative choledocoduodenal bypass the operating suites were simple anatomophatological examination was in favor of a well differentiated adenocarcinoma compatible with the pancreatic orogen known to the patient. 

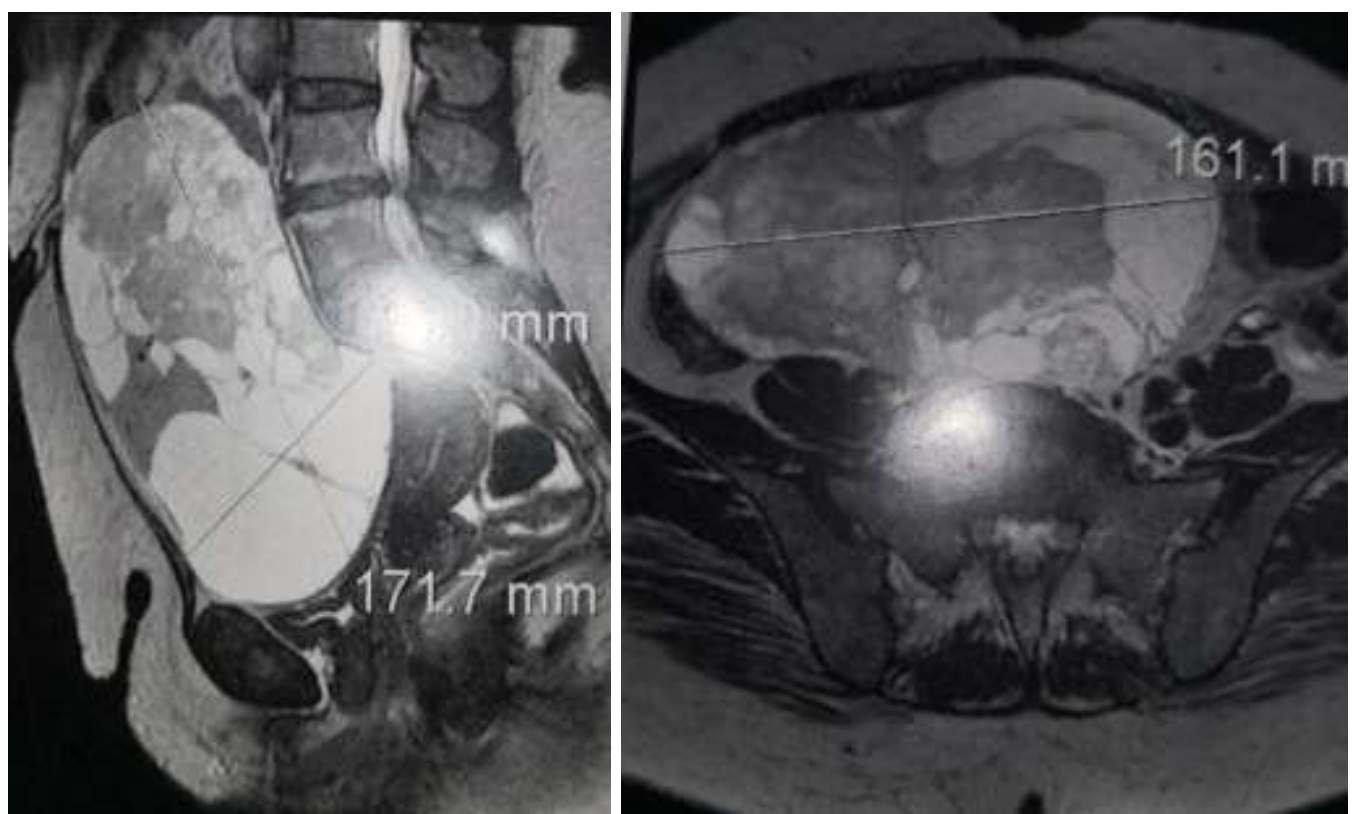

Fig-1: MRI showing lobulated masses with cystic and soft tissue components

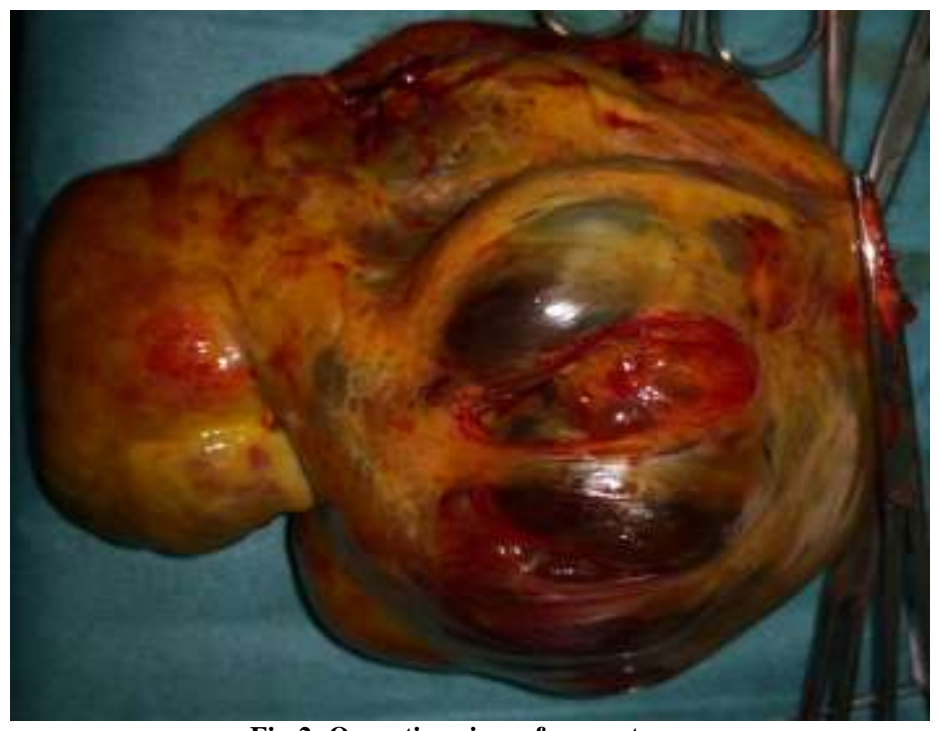

Fig-2: Operative piece of ovarectomy

\section{DISCUSSION}

\section{Metastatic}

pancreaticobiliary

tract adenocarcinomas in the ovary are notorious for their ability to simulate primary ovarian mucinous tumors [1], This tumor is named after Friedrich Ernst Krukenberg (1871-1946), who reported a new type of ovarian malignancy in 1896 . This was discovered to be metastatic in origin from primary gastrointestinal site 6 years later [2].

The average age of diagnosis is 45 years, symptoms are non specific: abdominal and pelvic pain, bloating, ascites or dyspareunia. These tumors can become autonomous and produce hormones leading to vaginal bleeding, menstrual cycle irregularities, hirsutism, or rarely virilization [3]. Pre-operative level for serum CA-125 can be elevated and decreases after tumor resection [3].
The current literature demonstrates that variability exists in the radiologic features of Krukenberg tumors. On CT and MRI, the tumors may appear complex, with both cystic and solid components and also range in size from 5 to $46 \mathrm{~cm}$ [4] In some cases, Krukenberg tumors may appear radiologically similar to primary ovarian cancer, with CT findings of large, lobulated masses with cystic and soft tissue components [5]. US can also characterize Krukenberg tumors and possibly suggest a primary site. Testa et al. found that Krukenberg tumors from the stomach or breast were mostly solid, whereas those from the colon or biliary tract were multilocular [6].

No optimal treatment strategy for these tumors has been established. A retrospective analysis showed that patients who underwent palliative surgeries including unilateral or bilateral salpingo-opherectomy alone, or a total hyseterectomy combined with bilateral 
salpingo-opherectomy, had a median overall survival of 17 months [7].

Prognosis: Patients usually die in 2 years with a median survival of 14 months reported in the Literature [8].

From a pathologic perspective, mucinous tumors of the ovaries are challenging when it comes to determining primary versus metastatic lesions. literature review, show that immunohistochemical staining with MUC1 is the most helpful stain that could help differentiate mucinous carcinoma form pancreaticobilary metastasis to the ovary from primary mucinous ovarian carcinoma [9].

\section{Conclusion}

Metastatic mucinous carcinomas to the ovary mimic their primary mucinous ovarian counterparts and their clinical and histopathological features overlap in many ways. The diagnosis and management of krukenberg tumor is complex and should involve an interprofessional team that includes hospice, palliative care nurse, pain specialist, oncologist, surgeon, pathologist, and radiologist. In all cases, this is metastatic disease and the patients are frail and debilitated. Aggressive surgery is not recommended as it does not extend life span.

Competing interests: All authors declare no financial relationships or conflicts of interest

\author{
Authors' contributions \\ Principal author: DAHMANE Hicham \\ $1^{\text {st }}$ co-autor: Alazaoui Faysal \\ Senior: Pr Belkouchi Abdelkader
}

Acknowledgements: No acknowledgements

\section{REFERENCES}

1. Young RH, Hart WR. Metastases from carcinomas of the pancreas simulating primary mucinous tumors of the ovary. A report of seven cases. The American journal of surgical pathology. 1989 Sep 1;13(9):748-56.

2. Al-Agha OM, Nicastri AD. An in-depth look at Krukenberg tumor: an overview. Arch. Pathol. Lab. Med. 2006 Nov; 130(11):1725-30.

3. Aziz M, Kasi A. Cancer, Krukenberg Tumor. InStatPearls [Internet] 2019 Dec 26. StatPearls Publishing.

4. Hoeppner C, Schlumbrecht MP, Brofman N, Pinto A, Hosein, Castillo RP. Pancreatic Krukenberg Tumor of the Ovary: A Case Series. J Clin Res Radiol. 2018;1(2):1-7.

5. Cho KC, Gold BM. Computed tomography of Krukenberg tumors. AJR Am J Roentgenol. 1985; 145:285-8.

6. Testa AC, Ferrandina G, Timmerman D, Savelli L, Ludovisi M, Van Holsbeke C, Malaggese M, Scambia G, Valentin L. Imaging in gynecological disease (1): ultrasound features of metastases in the ovaries differ depending on the origin of the primary tumor. Ultrasound in Obstetrics and Gynecology: The Official Journal of the International Society of Ultrasound in Obstetrics and Gynecology. 2007 May;29(5):505-11.

7. Seow-En I, Hwarng G, Tan GHC, Ho LML, Teo MCC. Palliative surgery for Krukenberg tumors 12-year experience and review of the literature. World J Clin Oncol. 2018 Feb 10;9(1):13-19.

8. Wu F, Zhao X, Mi B, Feng LU, Yuan NA, Lei F, Li M, Zhao X. Clinical characteristics and prognostic analysis of Krukenberg tumor. Molecular and clinical oncology. 2015 Nov 1;3(6):1323-8.

9. Ackroyd SA, Goetsch L, Brown J, Houck K, Wang C, Hernandez E. Pancreaticobiliary metastasis presenting as primary mucinous ovarian neoplasm: A systematic literature review. Gynecologic oncology reports. 2019 May 1;28:109-15. 